\title{
Clinicopathological correlation of uterine cervical lesions with focus on premalignant and malignant lesions
}

\author{
Ramesh Makaju$^{1}$, Binod Dhakal ${ }^{1}$, Rachana Dhakal ${ }^{1}$ \\ ${ }^{\prime}$ Department of Pathology, Dhulikhel hospital, Kathmandu University Hospital, Dhulikhel, Kavrepalanchowk, Nepal
}

\section{Keywords: \\ Adenocarcinoma; Carcinoma; Cervical cancer; Precancerous Lesion; Unhealthy cervix;}

\section{ABSTRACT}

Background: Cervical cancer ranks as the most frequent cancer among women in Nepal and the first most frequent cancer among women between 15 and 44 years of age. The objectives of the study are to find the incidence of premalignant and malignant cervical conditions and to correlate histopathological diagnosis with that of clinical diagnosis.

Materials and Methods: This was a retrospective study carried out at Kathmandu University Hospital. All cervical biopsy done from January 2009 to December 2018, were included in the study. A proforma was created in which relevant demographic data like age, sex along with clinical findings, gross and histopathological findings were collected.

Results: Mean age of patients with cervical intraepithelial lesion- 1, 2 and 3 was 43.5 years, 48 years and 43.4 years respectively. The most common diagnosis was cervical polyp were (38.65\%) followed by 52 cases $(15.9 \%)$ of unhealthy cervix which bleeds easily on touch and $42(12.8 \%)$ cases of inflammatory condition. Clinical diagnosis of carcinoma of cervix comprised of 42 cases (12.8\%). On histopathology, $51(15.6 \%)$ cases had invasive carcinoma of which $48(94.1 \%)$ were squamous cell carcinoma, two (3.92\%) were adenocarcinoma, and one (1.9\%) was of small cell carcinoma. In 33 cases (78.57\%), clinical examination was correctly able to identify the invasive cancer. The sensitivity rate of diagnosing cancerous and precancerous lesions by clinical examination and cervical pap smear was 80.95 percent.

Conclusion: Proper clinical history, examination, pap smearing and biopsy report helps through appropriate clinical intervention and prevents development of advanced stage of cervical carcinoma.

\section{Correspondence:}

Dr Ramesh Makaju Shrestha

Associate professor, Kathmandu University School

of Medical Sciences, Dhulikhel, Nepal

ORCID ID: 0000-0001-5492-9024

Email:makajuram@yahoo.com

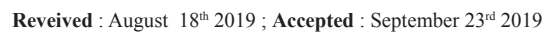

Citation: Makaju R, Dhakal B, Dhakal R. Clinicopathological correlation of uterine cervical lesions with focus on premalignant and malignant lesions. J Pathol Nep 2019;9:1560-3. DOI 10.3126/jpn. v9i2.26447

Copyright: This is an open-access article distributed under the terms of the Creative Commons Attribution 4.0 International License, which permits unrestricted use, distribution, and reproduction in any medium, provided the original author and source are credited.

\section{INTRODUCTION}

Cervical cancer is the second most common cancer in women worldwide. ${ }^{1}$ Almost 2,50,000 women die each year as a consequence of this disease. Approximately 311000 women died from cervical cancer. ${ }^{2}$ In developed countries, cervical screening program has dramatically reduced rates of cervical cancers. ${ }^{3}$ However, even in developed countries, the situation is not ideal either. The incidence in US was 7 per 100,000 women in 2004 ranking 8th most common cancer of women. ${ }^{4}$ In UK, the incidence was 8.5 per 100,000 in 2006 and ranks $12^{\text {th }}$ most common cancer of women. In India, the incidence of carcinoma of cervix is 
estimated to be 1,30,000 new cases every year and accounts for $86-90 \%$ of all genital cancers. ${ }^{5}$ Based on 2008-2010 the figure of 1 in 135 women $(0.7 \%)$ who will be diagnosed with cervical cancer during their life time is sobering as well as staggering. ${ }^{4}$

Cervical cancer ranks as the most frequent cancer among women in Nepal and the first most frequent cancer among women between 15 and 44 years of age. The World Health Organization estimates that a crude incidence rate of cervical cancer in Nepal is 24.2 per 100,000 women per year, with 3,504 new cases diagnosed every year and 1,872 deaths. $^{7}$ About $2.0 \%$ of women in the general population are estimated to harbor cervical HPV 16/18 infection at any given time, and approximately $80 \%$ of cervical cancers are attributed to HPVs 16 or $18 .^{7}$ All these statistics are so saddening and utterly unfortunate because precancerous cervical lesions can be found by cervical cancer screening Papanicolaou (Pap) smears (introduced more than half-acentury ago) and treated and cured before they develop into cancer.

The objectives of the study are to find the incidence of premalignant and malignant cervical conditions and to correlate histopathological diagnosis with that of clinical diagnosis.

\section{MATERIALS AND METHODS}

This was a retrospective study carried out at Dhulikhel Hospital, Kathmandu University Hospital (DHKUH). Ethical clearance was obtained from Institutional review committee of the DHKUH. All the incisional cervical biopsy done from January 2009 to December 2018, of which medical data were available were included in the study. Hysterectomy specimens and patients with insufficient data were not included in the study. A proforma was created in which relevant demographic data like age, sex along with clinical findings, gross and histopathological findings were collected. If required slides and block of the specific patients were retrieved and reviewed by the pathologist. Approval from Institution review committee of DHKUH was obtained for the use of all data.

\section{Statistical Analysis}

All the information was coded and entered into SPSS version 21. Continuous variables were presented using descriptive statistics and categorical variables were presented in the form of frequency table. Diagnostic concordance of malignancy between clinical and histopathology was calculated by dividing the number of concordant cases by the total number of patients. P-value were calculated and value less than 0.05 was considered statistically significant.

\section{RESULTS}

During the study period a total of 326 patients had cervical tissue biopsy and had sufficient available date to include in the study. Age of the patients ranges from 22 to 72 years with the mean age of 40 years. Age-wise distribution of cervical carcinoma is given in figure 1 in which most common age group was $41-50$ years.

Mean age of patients with CIN 1 was 43.5 years, CIN 2 was 48 years and CIN 3 was 43.4 years. Pathological diagnosis of Invasive carcinoma has an age range from 40 to 80 years and a mean age of 53.97 years.

Among the 326 patients the most common clinical diagnosis was cervical polyp (38.65\%) followed by 52 cases $(15.9 \%)$ of unhealthy cervix which bleeds easily on touch and 42 $(12.8 \%)$ cases of inflammatory condition. Clinical diagnosis of carcinoma of cervix comprised of 42 cases (12.8\%). ( Table 1)

Histopathologically, 51(15.596\%) cases were of invasive carcinoma of which 48 (94.1\%) were squamous cell carcinoma, two $(3.92 \%)$ cases were adenocarcinoma, and one $(1.9 \%)$ case was of small cell carcinoma. Other histopathological findings are shown in table 1.

In 33 cases (78.57\%), clinical examination was correctly able to identify the invasive cancer. The sensitivity rate of diagnosing cancerous and precancerous conditions is $80.95 \%$. The $\mathrm{p}$ value of correct clinical diagnosis of malignant and benign cases is $<0.01$, which is statistically significant. However, $52.94 \%$ cases were falsely diagnosed as suspicious for malignancy clinically. Similarly four $(13.79 \%)$ cases of per vaginal bleeding had invasive carcinoma and $1(1.92 \%)$ case of unhealthy cervix showed presence of invasive carcinoma. (Table 1) The sensitivity and specificity (including premalignant lesion) of the test were $65.7 \%$ and $95.2 \%$ respectively. Similarly positive predictive value and Negative predictive value were $80.64 \%$ and $90.15 \%$ respectively.

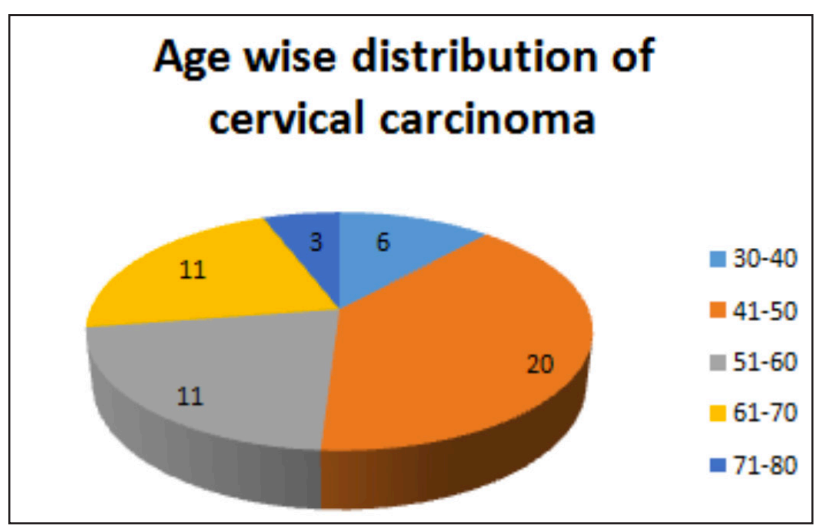

Figure 1: Age-wise distribution of cervical carcinoma 
Table 1: Clinical diagnosis of cervical biopsy and their final pathological diagnosis

\begin{tabular}{|c|c|c|c|c|c|c|}
\hline \multirow[b]{2}{*}{ Clinical diagnosis } & \multicolumn{5}{|c|}{ Histopathological diagnosis } & \multirow{2}{*}{$\begin{array}{l}\text { Total } \\
\text { n (\%) }\end{array}$} \\
\hline & $\begin{array}{l}\text { Pathological } \\
\text { Benign cases (\%) }\end{array}$ & Carcinoma (\%) & CIN III (\%) & CIN II (\%) & CIN I (\%) & \\
\hline $\begin{array}{l}\text { Carcinoma } \\
\text { cervix }\end{array}$ & $8 / 42(19.04)$ & $33 / 42(78.57)$ & $1 / 42(2.38)$ & 0 & 0 & $42(12.84)$ \\
\hline $\begin{array}{l}\text { Suspicious of } \\
\text { carcinoma }\end{array}$ & $18 / 34(52.94)$ & $13 / 34(38.23)$ & $2 / 34(5.88)$ & - & $1 / 34(2.94)$ & $34(10.39)$ \\
\hline $\begin{array}{l}\text { Inflammatory } \\
\text { conditions }\end{array}$ & $39 / 42(92.85)$ & - & $3 / 42(7.15)$ & - & - & $42(12.84)$ \\
\hline Bleeding & $22 / 29(75.86)$ & $4 / 29(13.79)$ & $1 / 29(3.44)$ & $1 / 29(3.44)$ & $1 / 29(3.44)$ & $29(8.86)$ \\
\hline Unhealthy cervix & $50 / 52(96.15)$ & $1 / 52(1.92)$ & $1 / 52(1.92)$ & - & - & $52(15.90)$ \\
\hline Polyp & $127 / 127(100)$ & - & - & - & & 127 \\
\hline Total & $264(80.73)$ & $51(15.64)$ & $8(2.44)$ & $1(0.3)$ & $2(0.61)$ & $326(100)$ \\
\hline
\end{tabular}

\section{DISCUSSION}

Histopathology helps classify the tumors in different types and remains important and widely used. ${ }^{8}$ A preneoplastic cervical intraepithelial neoplasia can regress, persist or progress towards invasive carcinoma. Thus, the goal of cervical cancer prevention program is to detect and treat all committed cancer precursors before invasion develops. ${ }^{9,10}$

Mean age of patient in present study of CIN 1 was 43.5 years, CIN 2 was 48 years, CIN 3 was 43.4 years, Invasive squamous cell carcinoma was 53.97 years and adenocarcinoma was 72 years which correlates with the mean ages observed by Gupta $\mathrm{M}$ et al and Fadare $\mathrm{O}$ et al. ${ }^{1,11}$

A total 11 cases of CIN were graded CIN 1 ( 2 cases: 18.18\%), CIN2 (1 case; 9.09\%) and CIN3; 72.7\%). However the study of Gupta $\mathrm{M}$ et al showed out of 36 cases, CIN 1 was $36.1 \%$, CIN 2 was $33.3 \%$, and CIN 3 was $30.6 \%{ }^{1}$ This contradicts our study. This might be because of the reluctance of pathologist in our institution to give CIN 1 as this may lead to excessive unnecessary interventions.

In the present study majority of uterine cervical lesions were non neoplastic, followed by neoplastic lesions. ${ }^{12}$ Cervical polyp was the commonest non neoplastic lesion. However the study of Jyothi $\mathrm{V}$ et al showed endocervical polyp to be just $4.1 \%$ which doesn't correlate with our study. ${ }^{13}$ The most frequent diagnosis in their study was Squamous cell carcinoma $44.4 \%$ followed by chronic cervicitis $30.53 \%$. However our study shows only $10.12 \%$ of squamous cell carcinoma. The frequency of different types of cervical malignancies in the present study is in accordance with other studies as shown in table $2 .{ }^{1,14,15,16,17,18}$

Our study showed the most frequent age of carcinoma cervix was 41 to 50 years. Pannayanapalya SS et al and Gaikwadi $\mathrm{S}$ et al agree with our study. ${ }^{18}$, However saini $\mathrm{S}$ et al showed the most frequent age group to be 51 to 60 years. ${ }^{20}$ Krishnappa C, Pannayanapalya SS showed the most common presentation of carcinoma cervix was per vaginal bleeding and vaginal discharge. ${ }^{18}$ This study also showed similar results.

Primary adenocarcinoma of the cervix is an unusual lesion. In recent years there has been a increase in the incidence of adenocarcinoma of the uterine cervix as shown in studies of Chen J et al. ${ }^{14}$ In the present study, adenocarinoma formed $3.92 \%$ of the total malignant tumours diagnosed in the uterine cervix. This result is comparable with the study of Gupta M et al which showed $8.1 \%$ of adenocarcinoma cases. ${ }^{1}$ Mean age of patients with adenocarcinoma of uterine cervix was 72 years. Few authors have reported that adenocarcinomas tend to occur in older population. However, recent study by Alfsen GC et al. and Gupta M et al have noticed a shift towards younger age. ${ }^{1}$

Table 2: Comparison of the types of cervical malignancy

\begin{tabular}{|c|c|c|c|c|c|}
\hline Studies & $\begin{array}{l}\text { Squamous cell } \\
\text { carcinoma }\end{array}$ & Adenocarcinoma & $\begin{array}{c}\text { Neuroendocarine } \\
\text { carcinoma }\end{array}$ & $\begin{array}{l}\text { Adenosquamous } \\
\text { carcinoma }\end{array}$ & Total \\
\hline Gupta M et al. ${ }^{1}$ & $85.1 \%$ & $8 \%$ & $5.4 \%$ & $1.3 \%$ & 74 \\
\hline Chen J et al. ${ }^{14}$ & $82.9 \%$ & $16.2 \%$ & $0.9 \%$ & - & 33048 \\
\hline Momtahen S et al. ${ }^{15}$ & $94.8 \%$ & $5.2 \%$ & - & - & 77 \\
\hline Lowe D et al. ${ }^{16}$ & $94.70 \%$ & $5.30 \%$ & - & - & 455 \\
\hline Brewer $\mathrm{R}$ et al. ${ }^{17}$ & $85.2 \%$ & $13.6 \%$ & - & $12.3 \%$ & 81 \\
\hline Pannayanapalya $S$ et al. ${ }^{18}$ & $97.9 \%$ & $2.01 \%$ & - & - & 199 \\
\hline Present study & $94.1 \%$ & $3.92 \%$ & $1.9 \%$ & - & 51 \\
\hline
\end{tabular}


In the present study, neuroendocrine tumours formed $1.9 \%$ of the total malignant lesions. Similar to the present study, Gupta $\mathrm{M}$ et al showed $5.4 \%$ of the cases and Wang $\mathrm{T}$ et al. reported $6 \%$ cases of large and small cell neuroendocrine tumours. ${ }^{1,22}$

The sensitivity of clinical examination especially by colposcopy in differentiating normal from abnormal cervical tissue ranged from $87 \%$ to $99 \%$ and the specificity ranged from $26 \%$ to $87 \%$. The positive predictive value ranged from $53 \%$ to $96 \%$, and the negative predictive value from $51 \%$ to $99 \% .{ }^{23}$ This is in concordance with our study except the sensitivity which is less.

Carcinoma cervix is more common in the low socioeconomic class, with lack of awareness of risk factors and presenting at an advanced stage. There is a need for national cervical screening and education program for women especially in rural areas. Study by Silfverdal L et al showed that histological assessment is strongly associated with decreased risk of invasive carcinoma compared to repeated cytology in women with low grade squamous abnormalities. ${ }^{24}$

\section{CONCLUSIONS}

Premalignant and malignant lesions in the cervix are frequent and the clinical diagnosis may show some discrepancies with the biopsy reports. Proper clinical history, examination, pap smearing and biopsy report help appropriate clinical intervention and prevents development of advanced stage of cervical carcinoma.

\section{Conflict of Interest: None}

\section{REFERENCES}

1. Gupta M, Basavaraj PK. Histopathological Spectrum of Premalignant and Malignant Lesions of Uterine Cervix. Nat Journal of Lab Med. 2018;7(1):19-26

2. Ferlay J, Ervik M, Lam F, Colombet M, Mery L, Piñeros M, Znaor A, Soerjomataram I, Bray F (2018). Global Cancer Observatory: Cancer Today. Lyon, France: International Agency for Research on Cancer. (Cited on 6th August 2019) Crossref

3. Husain N, Helali T, Domi M, Bedri S. Cervical cancer in women diagnosed at the National Health Laboratory, Sudan: A call for screening. Sudan JMS 2011;6:183-9.

4. Surveillance Epidemiological and End Results (SEER). SEER stat fact sheets: cervix uteri. (Cited on 6th August 2019). Crossref

5. Munagala R., Nagaranjan B. Alterations in cytokine levels in [1] cervical carcinoma patients through radiation therapy. Current Science. 2008;94(10):1292-6.

6. Nepal. Human Papillomavirus and Related Cancers, Fact Sheet 2015 (Dec 18, 2015). ICO HPV information cente. Cited on 6th August 2019) Crossref
7. Information Center on HPV and Cervical Cancer. Human papillomavirus and related cancers, fact sheet 2013. (Cited on 6th August 2019). Crossref

8. Jenkins D. Histopathology and cytopathology of cervical cancer. Disease Markers. 2007;23:199-212. Crossref

9. Sharma A, Rajappa M, Saxena A, Sharma M. Telomerase activity as a tumour marker in Indian women with cervical intraepithelial neoplasia and cervical cancer. Mol Diag Ther. 2007;11(3):193-201. Crossref

10. Gupta M, Basavaraj PK. Histopathological Spectrum of Premalignant and Malignant Lesions of Uterine Cervix. Nat Journal of Lab Med. 2018;7(1):19-26

11. Fadare O, Yi X, Liang SX, Ma Y, Zhang W. Variations of mitotic index in normal and dysplastic squamous epithelium of the uterine cervix as a function of endometrial maturation. Mod Pathol. 2007;20:1000-08. Crossref

12. Cubie HA, Seagar AL, McGoogan E, et al. Rapid real time PCR to distinguish between high risk human papillomavirus types 16 and 18 . Molecular Pathology 2001;54:24-29. Crossref

13. Jyothi V, Manoja V, Reddy SK. A clinicopathological study on cervix. J Evol Med Dent Sci. 2015;4(13):2100-6.

14. Chen J, Macdonald K, Gaffney DK. Incidence, mortality and prognostic factors of small cell carcinoma of the cervix. Obstet Gynecol. 2008;111:1394-402. Crossref

15. Momtahen S, Kadivar M, Kazzazi AS, Gholipour F. Assessment of gynecologic malignancies: A multicenter study in Tehran (19952005). Indian J Cancer. 2009;46(3):226-30. Crossref

16. Lowe D, Jorizzo J, Chiphangwi J, Hutt MSR. Cervical carcinoma in Malawi: A histopathologic study of 460 cases. Cancer. 1981;47:249395. $\underline{\text { Crossref }}$

17. Brewer R, Thanikachalam PM, Jun GW. Trend of cervical cancer in Seychelles. Seychelles Med Dent J. 1994;2(1):04-06.

18. Pannayanapalya SS, Kalyani R, Kai LJ, Narayanaswamy M. Clinicopathological Correlation of Cervical Carcinoma: A Tertiary Hospital Based Study. Asian Pac J Cancer. 2014;15(4):1671-4. Crossref

19. Sheela L, Gaikwad, Arvind GV, Agarwal NU.Clinicohistopathological analysis of lesions of uterine cervix in Ambejogai city of Maharashtra: A 2 year study at tertiary level hospital. J Diag Pathol Onco. 2016;1(2):32-5.

20. Saini S, Kanetkar SR. Clinico-histopathological study of cervical carcinoma at a tertiary care hospital. IOSR-JDM. 2017;16(2):61-9.

21. Hurt WG, Silverberg SG, Frable WJ, Belgrad R, Crooks LD. Adenocarcinoma of the cervix: histopathologic and clinical features. Am J Obstet Gynecol. 1977;129(3):304-15. Crossref

22. Wang T, Chen B, Yang Y, Chen H, Wang Y, Cviko A, et al. Histologic and immunophenotypic classification of cervical carcinomas by expression of the p53 homologue p63: A study of 250 cases. Hum Pathol. 2001;32(5):479-86. Crossref

23. Olaniyan OB. Validity of Colposcopy in the Diagnosis of Early Cervical Neoplasia - A Review.Afr J Reprod Health. 2002;6(3):5969. Crossref

24. Silfverdal L, Kemetli L, Andrae B, Sparen P, Ryd W, Diller J, et [28] al. Risk of invasive cervical cancer in relation to management of abnormal pap smear results. Am J Obstet Gynecol. 2009;201:188-91. Crossref 